\title{
Piper betle Leaf Extract Exhibits Anti-virulence Properties by Downregulating Rhamnolipid Gene Expression (rhIC) of Pseudomonas aeruginosa
}

\author{
Irene Ratridewi ${ }^{1,2 *}$, Shod Abdurrachman Dzulkarnain ${ }^{3}$, Andreas Budi Wijaya $^{2}$, Wisnu Barlianto ${ }^{2}$, Sanarto Santoso ${ }^{3}$, \\ Dewi Santosaningsih ${ }^{3}$ \\ ${ }^{1}$ Doctoral Program, Faculty of Medicine, Brawijaya University, Malang, East Java, Indonesia; ${ }^{2}$ Department of Pediatrics, Saiful \\ Anwar General Hospital, Faculty of Medicine, Brawijaya University, Malang, East Java, Indonesia; ${ }^{3}$ Department of Clinical \\ Microbiology, Saiful Anwar General Hospital, Faculty of Medicine, Brawijaya University, Malang, East Java, Indonesia
}

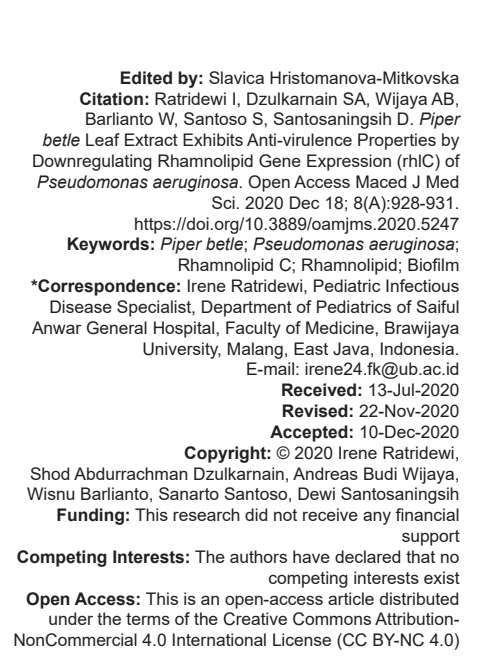

\section{Abstract}

BACKGROUND: Piper betle ( $P$. betle) is widely used as a traditional medicine in Indonesia, with anti-quorum sensing and anti-biofilm activity. We investigated the impact of methanolic leaf extract of $P$. betle against Pseudomonas aeruginosa's ( $P$. aeruginosa) virulence factor, which associated with rhamnolipid (rhl) genes,

METHODS: Minimum biofilm inhibitory concentration of the extract was determined at a concentration of $0.4 \%$ by agar dilution assay. The expression of rhIA and rhlC gene was assessed by using real-time polymerase chain reaction.

RESULTS: All $P$. aeruginosa isolates contained rhIA, rhlB, and rhlC genes, which associated with rhl production. The expression of the rhlC gene decreased after administration of $P$. betle leaf extract at concentration of $0.4 \%$, with beta coefficient was $0.662(p=0.019)$.

CONCLUSION: The methanolic leaf extract of $P$. betle shows inhibition of rhIC gene expression, indicating the antirhl properties of $P$. betle against $P$. aeruginosa infection.

\section{Introduction}

Pseudomonas aeruginosa ( $P$. aeruginosa) is Gram-negative bacteria which associated with a high fatality rate and antimicrobial resistance [1]. Biofilm formation is one of the main mechanisms of $P$. aeruginosa to protect itself from host's immune response and killing by antibiotics [2]. Quorum sensing (QS) pathway is an important determinant for biofilm formation of $P$. aeruginosa, including Las, rhamnolipid (rhl), pseudomonas quinolone signal, and integrated quorum-sensing signal systems [3], [4]. The rhl system is regulated by three genes: rhIA, rhIB, and rhIC, which encode corresponding proteins necessary in synthesis of rhl [5]. rhl plays important role in biofilm formation, especially for $P$. aeruginosa [4].

Piper betle ( $P$. betle) (Indonesian name Sirih hijau) is widely used as a traditional medicine in Indonesia. Its leaf extract has been investigated as potent anti-biofilm and also exhibited anti-QS activity, although the precise mechanism of action remains unclear [6], [7]. One of the most abundant compounds inside $P$. betle is eugenol, which exhibits powerful antioxidant activity [8]. Eugenol could suppress the expression of $P$. aeruginosa virulence factor such rhl and also inhibit biofilm formation [9], [10]. However, the influence of eugenol against rhl gene regulation has not been elucidated yet. We aimed to investigate the impact of methanolic leaf extract of $P$. betle against $P$. aeruginosa's virulence factor, which associated with rhl gene.

\section{Methods}

\section{Bacterial isolate}

$P$. aeruginosa clinical isolate was obtained from the bacterial culture collection in the Department 
of Clinical Microbiology, Faculty of Medicine, Brawijaya University and identification was confirmed by the Microbact $^{\mathrm{TM}}$ Gram-negative system.

\section{Plant material and extract preparation}

The $P$. betle leaves were collected from Malang, East Java, Indonesia. The species of Piperwas identified and confirmed by plant taxonomist of units of pulmonary toxicity dose Materia Medica, Batu, as herbarium unit in East Java, Indonesia. The extraction process was executed in Technical Chemistry Laboratory of State Polytechnic of Malang, Indonesia. The leaves were shade dried and ground into fine powder (30 g), then macerated in $100 \mathrm{ml}$ absolute methanol for $72 \mathrm{~h}$ by the extraction apparatus. The extract was evaporated to dry at $40^{\circ} \mathrm{C}$ by using a rotary evaporator and then stored at $4^{\circ} \mathrm{C}$ for further use.

\section{Determination of the minimum biofilm inhibitory concentration (MBIC)}

Agar dilution method was used to determine the MBIC of methanolic leaf extract of $P$. betle. Bacteria isolates were incubated for $24 \mathrm{~h}$ inside brain heart infusion liquid medium, then diluted to achieve $0.5 \mathrm{Mc}$ Farland. Then, the suspension was challenged with $P$. betle extract and incubated so that the biofilm formation and MBIC could be determined [11]. Two-fold serial dilutions of the extract $(0 \%, 0.05 \%, 0.1,0.2 \%$, $0.3 \%, 0.4 \%, 0.5 \%, 0.6 \%, 0.7 \%, 0.8 \%, 0.9 \%$, and $1.00 \%$ ) were prepared in Mueller-Hinton agar. Ten microliters of bacterial inoculum were delivered onto agar with a final inoculum of $10^{4} \mathrm{CFU} / \mathrm{spot}$. Bacterial plates were incubated at $37^{\circ} \mathrm{C}$ and evaluated after $24 \mathrm{~h}$.

\section{Detection of rhamnosyltransferase gene}

Gene expression of rhlAand rhIC were assessed using two-step quantitative real-time polymerase chain reaction $(P C R)$ in the Institute of Tropical Disease of Airlangga University, Surabaya, Indonesia [12]. Before PCR, RNA was first transcribed into cDNA, and in a second step, the quantitative real-time $\mathrm{PCR}$ was performed using a MyGo Mini Real-time PCR System in combination with GoTaq® qPCR Master Mix. Primers used for real-time PCR are listed in Supplementary Table 1. Before gene expression analyses, primers were checked for appropriate product amplification, and primer efficiencies were determined and target

Supplementary Table 1: Primers for rhamnosyltransferase gene detection

\begin{tabular}{lll}
\hline Notation & Sequence $5^{\prime} \rightarrow 3^{\prime}$ & $\begin{array}{l}\text { Expected length of the amplified } \\
\text { fragment }(\mathrm{bp})\end{array}$ \\
\hline rhIA F & GATCGAGCTGGACGACAAGTC & 95 \\
rhIA R & GCTGATGGTTGCTGGCTTTC & \\
rhIB F & GCCCACGACCAGTTCGAC & 226 \\
rhIB R & CATCCCCCTCCCTATGAC & \\
rhIC F & ATCCATCTCGACGGACTGAC & 159 \\
rhIC R & GTCCACGTGGTCGATGAAC & \\
\hline
\end{tabular}

specific efficiencies were then used for calculation of relative expression ratios. All primers used met the requirements as well as the tolerable efficiency range of $90-110 \%$ or were redesigned if otherwise. The bacteria were challenged by $P$. betle extract within $24 \mathrm{~h}$ before real-time PCR evaluation.

\section{Statistical analysis}

Gene expression data were obtained using the MyGo Mini Real-time PCR System software which is installed in Windows and subsequently analyzed using the same software, which calculates relative gene expression based on the delta-delta Ct method. Linear regression method was used to assess the correlation between $P$. betle extract and rhl gene expression using SPSS 23.0. Significant differences were accepted when $p<0.05$.

\section{Results and Discussion}

All $P$. aeruginosa isolates in this study contained rhlA, rhIB, and rhIC genes (Figure 1), which associated with rhl production. A previous report in our laboratory demonstrated that $P$. betle leaf extract was able to inhibit biofilm growth, with minimum inhibitory concentration reached by $0.4 \%$ concentration. The expression of rhlA gene did not significantly change after exposure to $P$. betle leaf extract, with a beta coefficient $0.242(p=0.384)$. $P$. betle leaf extracts have eugenol as an active compound; however, the concentration is not high enough to suppress rhlA gene expression. rhlA protein is responsible for 3-hydroxyalkanoyloxyalkalonic acid (HAA) synthesis [13].

Optimization test for rhlA and rhlC gene expression produced a normal curve at an annealing temperature of $60^{\circ} \mathrm{C}$, while quantification of the rhlB gene did not succeed in obtaining a normal curve, although the annealing temperature had been manipulated. It could be associated with the primary storage factor, but this possibility could be ruled out, as all three primers have the same storage requirements and also stored in the same manner and temperature. The rhlB gene is an intermediate gene, which activated by HAA and produced a catalyst from the rhamnosyltransferase subunit (RhIB) to form a mono-rhl. The expression of the catalyzed gene may be so short that it cannot be measured [14].

As rhamnosyltransferase enzyme, RhIB is responsible for the conjugation of HAA with dTDP-Lrhamnose to mono-rhl and RhIC. Then, RhIC will convert mono-rhl to di-rhl. The rhIA and rhIB genes are located on a single operon along the rhIRI system, while rhIC is located 2.5 $\mathrm{Mb}$ under the rhIRI operon [14]. It might explain why the rhIA gene was not directly affected by $P$. 


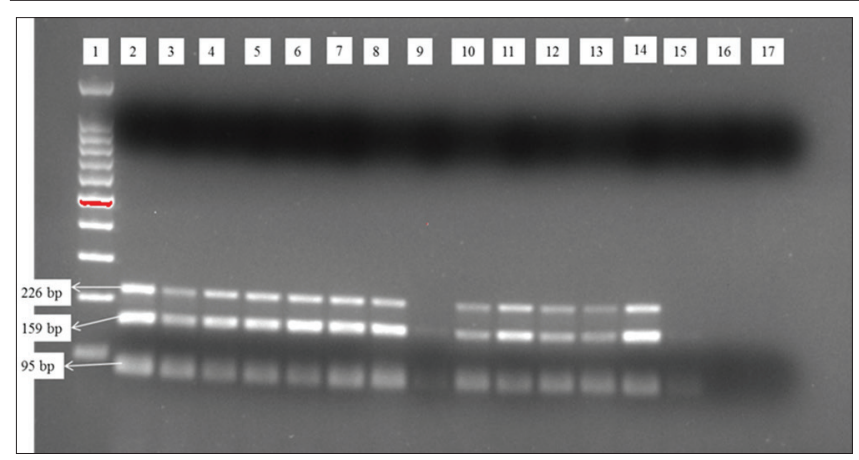

Figure 1: Identification of genes rhlA, rhlB, rhlC 1: DNA marker $100 \mathrm{bp}$; 2: Pseudomonas aeruginosa (14018); 3: Pseudomonas aeruginosa (14018); 4: Pseudomonas aeruginosa (13842); 5: Pseudomonas aeruginosa (13842); 6: Pseudomonas aeruginosa (14040); 7: Pseudomonas aeruginosa (14040); 8: Pseudomonas aeruginosa (14076); 9: Pseudomonas aeruginosa (14076); 10: Pseudomonas aeruginosa (14230); 11: Pseudomonas aeruginosa (14230); 12: Pseudomonas aeruginosa (14150); 13: Pseudomonas aeruginosa (14150); 14: positive control or wild-type strain (27853); 15: positive control or wild-type strain (27853); 16: negative control; 17: negative control. Gene identification used simple PCR method on a number of isolates, indicated that each clinical isolate had $\mathrm{rhl} A$ (95bp), rhl B (226bp), and rhl C (159bp) genes

betle extract administration. The rhIB gene expression could not be assessed because of an unidentifiable normal curve. However, rhlB gene does not play a single role in the QS system but works together with rhlA gene to form di-rhl. The rhlC gene is responsible for the formation of active rhl [4].

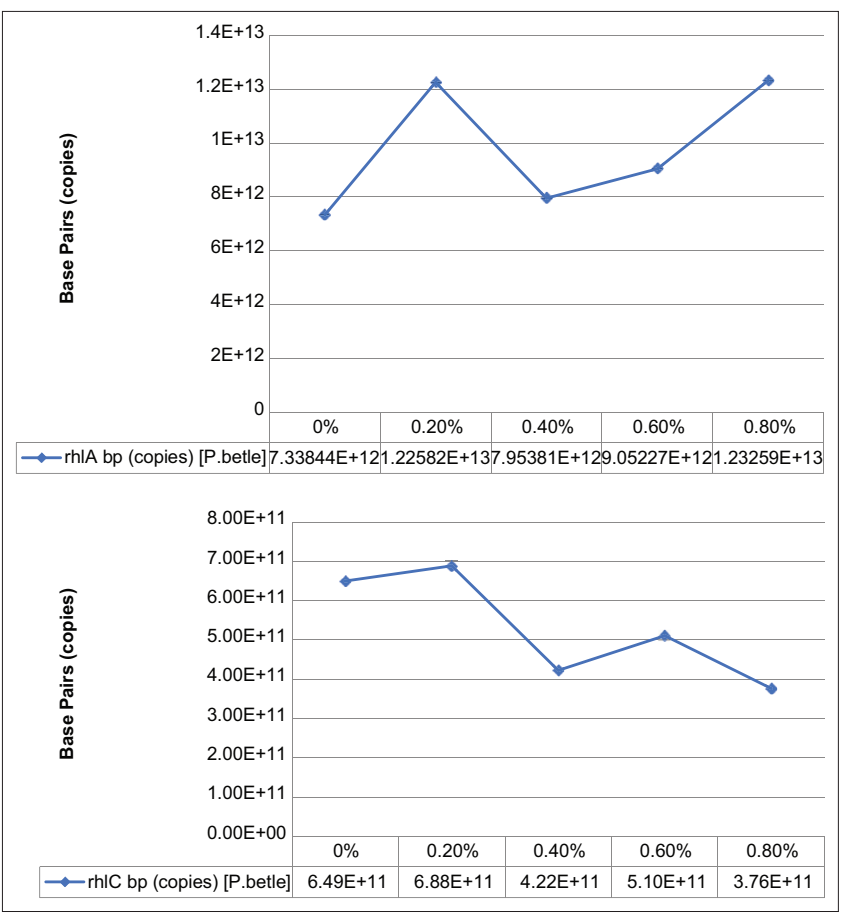

Figure 2: (a) Graph of rhIA gene quantification after exposure to Piper betle leaf extract. (b) Graph of rh/C gene quantification after exposure to Piper betle leaf extract

The expression of rhlC gene decreased after administration of $P$. betle leaf extract at concentration of $0.4 \%$, with a beta coefficient was $0.662(p=0.019)$ (Figure 2). The expression of this gene might be influenced by $P$. betle leaf extract. Eugenol that is present abundantly in $P$. betle leaf extract has the strongest potential effect on rhl itself and also the rhIC gene expression. It was consistent with a previous study, which showed that $P$. betle leaf extract will inhibit the expression of rhIC gene at MBIC concentration [15]. Bacteria which used in this study might be highly virulent so that rhlA gene was not affected by $P$. betle leaf extract administration.

\section{Conclusion}

$P$. betle methanolic leaf extract showed inhibition of rhlC gene expression, indicating anti-rhl properties against $P$. aeruginosa infection. Further studies are required to define appropriate dosing regimens for $P$. aeruginosa infections and to assess novel treatment strategies, including combination therapies with appropriate antibiotics.

\section{References}

1. Macia MD, Rojo-Molinero E, Oliver A. Antimicrobial susceptibility testing in biofilm-growing bacteria. Clin Microbiol Infect. 2014;20(10):981-90. https://doi.org/10.1111/1469-0691.12651 PMid:24766583

2. Vital-Lopez FG, Reifman J, Wallqvist A. Biofilm formation mechanisms of Pseudomonas aeruginosa predicted via genome-scale kinetic models of bacterial metabolism. PLoS Comput Biol 2015;11(10):e1004452. https://doi.org/10.1371/ journal.pcbi.1004452

PMid:26431398

3. Moradali MF, Ghods S, Rehm BH. Pseudomonas aeruginosa lifestyle: A paradigm for adaptation, survival, and persistence. Front Cell Infect Microbiol. 2017;7:39. https://doi.org/10.3389/ fcimb.2017.00039

PMid:28261568

4. Rasamiravaka T, Labtani Q, Duez P, El Jaziri M. The formation of biofilms by Pseudomonas aeruginosa. Biomed Res Int. 2015;2015:759348. https://doi.org/10.5772/intechopen.90833 PMid:25866808

5. Chong H, Li Q. Microbial production of rhamnolipids: Opportunities, challenges and strategies. Microb Cell Fact. 2017;16:137. https://doi.org/10.1186/s12934-017-0753-2

6. Teanpaisan R, Kawsud P, Pahumunto N, Puripattanavong J. Screening for antibacterial and antibiofilm activity in Thai medicinal plant extracts against oral microorganisms. J Tradit Complement Med. 2017;7(2):172-7. https://doi.org/10.1016/j. jtcme.2016.06.007

PMid:28417087

7. Datta S, Jana D, Raj T, Aveek M. Piper betle leaf extract affects the quorum sensing and hence virulence of Pseudomonas aeruginosa PAO1. Biotech. 2016;6(1):1-6. https://doi. org/10.1007/s13205-015-0348-8

PMid:28330090

8. Aara A, Chappidi V, Ramadas MN. Antioxidant activity of eugenol 
in Piper betel leaf extract. J Fam Med Prim Care. 2020;9(1):32731. https://doi.org/10.4103/jfmpc.jfmpc_809_19

\section{PMid:32110613}

9. Miladi H, Zmantar T, Kouidhi B, Chaabouni $Y$, Mahdouani $\mathrm{K}$ Bakhrouf $A$, et al. Use of carvacrol, thymol, and eugenol for biofilm eradication and resistance modifying susceptibility of Salmonella enterica serovar Typhimurium strains to nalidixic acid. Microb Pathog. 2017;104:56-63. https://doi.org/10.1016/j. micpath.2017.01.012

PMid:28062292

10. Lou Z, Letsididi KS, Yu F, Pei Z, Wang H, Letsididi R. Inhibitive effect of eugenol and its nanoemulsion on quorum sensing-mediated virulence factors and biofilm formation by Pseudomonas aeruginosa. J Food Prot. 2019;82(3):379-89. https://doi.org/10.4315/0362-028x.jp-18-196

PMid:30785306

11. Christensen GD, Bisno AL, Parisi JT, McLaughlin B, Hester MG, Luther RW. Nosocomial septicemia due to multiply antibioticresistant Staphylococcus epidermidis. Ann Intern Med. 1982;96(1):1-10. https://doi.org/10.7326/0003-4819-96-1-1 PMid:7053681

12. Ionescu R, Mereuta I, Pelinescu D, Csutak O, Tanase AM,
Vassu $T$, et al. Screening and molecular analyses for biosurfactant production by Pseudomonas aeruginosa strains from oil polluted soil. Rom Biotechnol Lett. 2019;24(4):692-6. https://doi.org/10.25083/rbl/24.4/692.696

13. Al-Shabib NA, Husain FM, Ahmad I, Baig MH. Eugenol inhibits quorum sensing and biofilm of toxigenic MRSA strains isolated from food handlers employed in Saudi Arabia. Biotechnol Biotechnol Equip. 2017;31(2):387-96. https://doi.org/10.1080/1 3102818.2017.1281761

14. Twigg MS, Tripathi L, Zompra A, Salek K, Irorere VU, Gutierrez $\mathrm{T}$, et al. Identification and characterisation of short chain rhamnolipid production in a previously uninvestigated, non-pathogenic marine pseudomonad. Appl Microbiol Biotechnol. 2018;102(19):8537-49. https://doi.org/10.1007/ s00253-018-9202-3

PMid:29992435

15. Ahmed SA, Rudden M, Smyth TJ, Dooley JS, Marchant R, Banat IM. Natural quorum sensing inhibitors effectively downregulate gene expression of Pseudomonas aeruginosa virulence factors. Appl Microbiol Biotechnol. 2019;103(8):352135. https://doi.org/10.1007/s00253-019-09618-0

PMid:30852658 